\title{
Quem influencia a Pós-Graduação em Direito no Brasil? Uma Análise Empírica da Nucleação Acadêmica
}

\author{
Who influences the Post-Graduation Law Courses in Brazil?
}

An empirical analysis

Marcelo Varella

Doutor em Direito (Sorbonne). Pós-Doutor (Berkeley, George Washington University). Livre-Docente (USP). Pesquisador do CNPq. E-mail: marcelodvarella@gmail.com

\section{Resumo}

Nucleação acadêmica é a influência direta que um programa tem sobre a formação do conhecimento no país. Ela é mensurada por meio de dois principais indicativos. O primeiro é que seus egressos tornem-se professores em outros programas de mestrado e doutorado. O segundo é a influência direta do conhecimento nela produzido na construção do saber em uma determinada área. Este artigo se concentra sobre o primeiro ponto. Foram analisados os corpos docentes de todos os programas de pós-graduação em Direito existentes em 2012, ou seja, aqueles que preencheram o sistema de Coleta de Dados da Capes, ainda que não avaliados na avaliação trienal 2010-2012. Em seguida, buscou-se identificar em que local se titularam. Na última parte, os dados empíricos são analisados, de forma crítica.

Palavras-chaves: Nucleação acadêmica; Universidades mais importantes no Brasil em Direito; Endogenia

\begin{abstract}
Academic influence can be measured by two ways. The first is to identify how many former $\mathrm{PhD}$ students that obtained the degree in a certain university become professors inother master's and doctoral programs. The second is the direct influence of the knowledge produced in a particular area it. This papers focuses on the first method. I analysed the faculty staff of all graduate programs in law existing in 2012, ie, those who sent the DataCapes, event those not evaluated in the assessment for 2010-2012. Next, I sought to identify where they obtained their Doctoral Degree. In the last part, there is a critical analysis of the data colected.
\end{abstract}


Keywords: academic influention, most important universities on Law in Brazil; Endogeny

Nucleação acadêmica é a influência direta que um programa tem sobre a formação do conhecimento no país. Ela é mensurada por meio de dois principais indicativos. O primeiro é que seus egressos tornem-se professores em outros programas de mestrado e doutorado. O segundo é a influência direta do conhecimento nela produzido na construção do saber em uma determinada área. Este artigo se concentra sobre o primeiro ponto.

A titulação de Doutores, que se tornarão docentes de mestrado e doutorado, significa a possibilidade de multiplicar o conhecimento produzido institucionalmente. Não apenas forma-se "professores de professores", mas se forma para todo o país.

A pós-graduação em Direito no Brasil está em rápida expansão. Nos últimos dez anos, o número total de cursos saltou de pouco mais de 20 para cerca de 80 . O número de Doutorados em Direito avançou de pouco mais de cinco cursos para 31. Com o avanço dos cursos com conceito 4 na última avaliação trienal, em 2013, existe um potencial de aumento para quase 50 cursos de doutorado em Direito. ${ }^{1}$ Estes números significam que o Brasil será o país com a maior pós-graduação em Direito do mundo.

Atualmente, há pouquíssimos juristas brasileiros reconhecidos no exterior. O país está fora das redes de pesquisa mais importantes. O Brasil é, sem dúvida, um país periférico na produção do conhecimento jurídico mundial. O desafio é como transformar a maior pós-graduação em Direito do mundo em uma das melhores ou mais influentes.

Esse desafio está relacionado com o modelo de academia existente no país. Os centros mais influentes de produção de conhecimento, conhecidos como centros nucleadores, têm um dever social de pensar a pós-graduação do Brasil como um todo, de criar padrões de qualidade nacionais e políticas institucionais de influência nacional. Estes cursos são premiados com o conceito 6 e 7 da Capes. Além do prestígio, isso significa ter acesso prioritários a recursos públicos para montagem de redes de pesquisa,

\footnotetext{
${ }^{1}$ VARELLA, M. D. e BARRETO, M. M. Políticas de revalidação de diplomas de pós-graduação em Direito no Brasil: dificuldades e desafios para o sistema brasileiro in Revista Brasileira de Polítcas Públicas, v. 2, n. 1p. 143-161
} 
além de uma taxa de bancada no âmbito do Proex, que pode variar entre $\mathrm{R} \$ 300$ mil para os cursos nível 6 a $\mathrm{R} \$ 1$ milhão para os cursos nível 7. Em outras palavras, o Governo Federal investe mais recursos nos cursos excelentes, com a expectativa de que tais cursos espalhem sua excelência pelo país e tornem-se mais influentes no mundo. ${ }^{2}$

Mas quais são os cursos que realmente são nucleadores para a área de Direito? Com base em apenas um dos critérios, este artigo irá analisar o perfil dos cursos nucleadores e as notas que têm na pós-graduação. Como se trata de pesquisa puramente empírica, que coleta dados na Plataforma Sucupira e os discute diretamente, não há muita discussão teórica. Além disso, não encontramos outras fontes bibliográficas específicas sobre o conceito de nucleação, mesmo em outras áreas relacionadas.

\section{Descrição da metodologia utilizada}

Foram analisados os corpos docentes de todos os programas de pós-graduação em Direito existentes em 2012, ou seja,aqueles que preencheram o sistema de Coleta de Dados da Capes, ainda que não avaliados na avaliação trienal 2010-2012.

Assim, os cursos avaliados foram:

\begin{tabular}{|l|l|l|l|}
\hline $\begin{array}{l}\text { Centro } \\
\text { Universitário de } \\
\text { (UNItiba }\end{array}$ & $\begin{array}{l}\text { Centro } \\
\text { Universitário } \\
\text { de Brasília } \\
\text { (UNICEUB) }\end{array}$ & $\begin{array}{l}\text { Centro } \\
\text { Universitário } \\
\text { do Estado do } \\
\text { Pará } \\
\text { (CESUPA) }\end{array}$ & $\begin{array}{l}\text { Centro } \\
\text { Universitário do } \\
\text { Maranhão } \\
\text { (Uniceuma) }\end{array}$ \\
\hline $\begin{array}{l}\text { Centro } \\
\text { Universitário Fieo } \\
\text { (UNIFIEO) }\end{array}$ & $\begin{array}{l}\text { Centro } \\
\text { Universitário } \\
\text { Ritter dos Reis } \\
\text { (Uniritter) }\end{array}$ & $\begin{array}{l}\text { Centro } \\
\text { Universitário } \\
\text { Salesiano } \\
\text { (UNISAL) }\end{array}$ & $\begin{array}{l}\text { Escola Superior } \\
\text { Helder Câmara } \\
\text { (ESDHC) }\end{array}$ \\
\hline $\begin{array}{l}\text { Faculdade } \\
\text { Antônio Carlos } \\
\text { (UNIPAC) }\end{array}$ & $\begin{array}{l}\text { Faculdade } \\
\text { Autônoma de } \\
\text { Direito } \\
\text { (FADISP) }\end{array}$ & $\begin{array}{l}\text { Faculdade de } \\
\text { Direito de } \\
\text { Vitória (FDV) }\end{array}$ & $\begin{array}{l}\text { Faculdade de } \\
\text { Direito Sul de } \\
\text { Minas (FDSM) }\end{array}$ \\
\hline $\begin{array}{l}\text { Faculdade de } \\
\text { Direito Milton } \\
\text { Campos (Famc) }\end{array}$ & $\begin{array}{l}\text { Faculdades } \\
\text { Integradas do } \\
\text { Brasil } \\
\text { (UniBrasil) }\end{array}$ & $\begin{array}{l}\text { Faculdades } \\
\text { Metropolitanas } \\
\text { Unidas (FMU) }\end{array}$ & $\begin{array}{l}\text { Fundação de } \\
\text { Ensino } \\
\text { Eurípedes } \\
\text { Rocha } \\
\text { (UNIVEM) }\end{array}$ \\
\hline $\begin{array}{l}\text { Fundação Getúlio } \\
\text { Vargas (FGV) }\end{array}$ & $\begin{array}{l}\text { Instituição } \\
\text { Toledo de } \\
\text { Ensino (ITE) }\end{array}$ & $\begin{array}{l}\text { Instituto } \\
\text { Brasiliense de } \\
\text { Direito Público } \\
\text { (IDP) }\end{array}$ & $\begin{array}{l}\text { Pontifícia } \\
\text { Universidade } \\
\text { Católica de } \\
\text { Minas Gerais }\end{array}$ \\
\hline
\end{tabular}

${ }^{2}$ https://sucupira.capes.gov.br/sucupira/public/consultas/coleta/programa/listaPrograma.jsf 


\begin{tabular}{|c|c|c|c|}
\hline & & & (PUCMG) \\
\hline $\begin{array}{l}\text { Pontifícia } \\
\text { Universidade } \\
\text { Católica de São } \\
\text { Paulo (PUCSP) }\end{array}$ & $\begin{array}{l}\text { Pontifícia } \\
\text { Universidade } \\
\text { Católica do } \\
\text { Rio de Janeiro } \\
\text { (PUCRJ) }\end{array}$ & $\begin{array}{l}\text { Pontifícia } \\
\text { Universidade } \\
\text { Católica do Rio } \\
\text { Grande do Sul } \\
\text { (PUCRGS) }\end{array}$ & $\begin{array}{l}\text { Universidade } \\
\text { Cândido } \\
\text { Mendes } \\
\text { (UCAM) }\end{array}$ \\
\hline $\begin{array}{l}\text { Universidade } \\
\text { Católica de } \\
\text { Brasília (UCB) }\end{array}$ & $\begin{array}{l}\text { Universidade } \\
\text { Católica de } \\
\text { Pernambuco } \\
\text { (Unicap) }\end{array}$ & $\begin{array}{l}\text { Universidade } \\
\text { Católica de } \\
\text { Petrópolis } \\
\text { (UCP) }\end{array}$ & $\begin{array}{l}\text { Universidade } \\
\text { Católica de } \\
\text { Santos } \\
\text { (UNISANTOS) }\end{array}$ \\
\hline $\begin{array}{l}\text { Universidade de } \\
\text { Brasília (UNB) }\end{array}$ & $\begin{array}{l}\text { Universidade } \\
\text { de Fortaleza } \\
\text { (UniFor) }\end{array}$ & $\begin{array}{l}\text { Universidade } \\
\text { de Itaúna (UI) }\end{array}$ & $\begin{array}{l}\text { Universidade } \\
\text { de Marília } \\
\text { (UNIMAR) }\end{array}$ \\
\hline $\begin{array}{l}\text { Universidade de } \\
\text { Ribeirão Preto } \\
\text { (UNAERP) }\end{array}$ & $\begin{array}{l}\text { Universidade } \\
\text { de Santa Cruz } \\
\text { do Sul } \\
\text { (UNISC) }\end{array}$ & $\begin{array}{l}\text { Universidade } \\
\text { de São Paulo } \\
\text { (USP) }\end{array}$ & $\begin{array}{l}\text { Universidade di } \\
\text { Estado de Rio } \\
\text { de Janeiro } \\
\text { (UERJ) }\end{array}$ \\
\hline $\begin{array}{l}\text { Universidade do } \\
\text { Vale do Itajaí } \\
\text { (Univali) }\end{array}$ & $\begin{array}{l}\text { Universidade } \\
\text { do Vale do } \\
\text { Rio dos Sinos } \\
\text { (UNISINOS) } \\
\end{array}$ & $\begin{array}{l}\text { Universidade } \\
\text { Estácio de Sá } \\
\text { (Unesa) }\end{array}$ & $\begin{array}{l}\text { Universidade } \\
\text { Estadual de } \\
\text { Londrina (UEL) }\end{array}$ \\
\hline $\begin{array}{l}\text { Universidade } \\
\text { Estadual do } \\
\text { Amazonas (UEA) }\end{array}$ & $\begin{array}{l}\text { Universidade } \\
\text { Estadual do } \\
\text { Norte do } \\
\text { Paraná } \\
\text { (UENP) }\end{array}$ & $\begin{array}{l}\text { Universidade } \\
\text { Estadual } \\
\text { Paulista } \\
\text { (UNESP) }\end{array}$ & $\begin{array}{l}\text { Universidade } \\
\text { Federal da } \\
\text { Bahia (UFBA) }\end{array}$ \\
\hline $\begin{array}{l}\text { Universidade } \\
\text { Federal da Paraíba } \\
\text { (UFPB) }\end{array}$ & $\begin{array}{l}\text { Universidade } \\
\text { Federal de } \\
\text { Alagoas } \\
\text { (UFAL) }\end{array}$ & $\begin{array}{l}\text { Universidade } \\
\text { Federal de } \\
\text { Minas Gerais } \\
\text { (UFMG) }\end{array}$ & $\begin{array}{l}\text { Universidade } \\
\text { Federal de } \\
\text { Pernambuco } \\
\text { (UFPE) }\end{array}$ \\
\hline $\begin{array}{l}\text { Universidade } \\
\text { Federal de Santa } \\
\text { Catarina (UFSC) }\end{array}$ & $\begin{array}{l}\text { Universidade } \\
\text { Federal de } \\
\text { Sergipe (UFS) }\end{array}$ & $\begin{array}{l}\text { Universidade } \\
\text { Federal de } \\
\text { Uberlândia } \\
\text { (UFU) }\end{array}$ & $\begin{array}{l}\text { Universidade } \\
\text { Federal do } \\
\text { Ceará (UFC) }\end{array}$ \\
\hline $\begin{array}{l}\text { Universidade } \\
\text { Federal do } \\
\text { Espírito Santo } \\
\text { (UFES) }\end{array}$ & $\begin{array}{l}\text { Universidade } \\
\text { Federal do } \\
\text { Estado do Rio } \\
\text { de Janeiro } \\
\text { (Unirio) }\end{array}$ & $\begin{array}{l}\text { Universidade } \\
\text { Federal do } \\
\text { Goiás (UFG) }\end{array}$ & $\begin{array}{l}\text { Universidade } \\
\text { Federal do } \\
\text { Maranhão } \\
\text { (UFMA) }\end{array}$ \\
\hline $\begin{array}{l}\text { Universidade } \\
\text { Federal do Mato } \\
\text { Grosso (UFMT) }\end{array}$ & $\begin{array}{l}\text { Universidade. } \\
\text { Federal. do } \\
\text { Pará (UFPA) }\end{array}$ & $\begin{array}{l}\text { Universidade } \\
\text { Paraná (UFPR) }\end{array}$ & $\begin{array}{l}\text { Universidade } \\
\text { Federal do Rio } \\
\text { de Janeiro } \\
\text { (UFRJ) }\end{array}$ \\
\hline $\begin{array}{l}\text { Universidade } \\
\text { Federal do Rio } \\
\text { Grande do Norte } \\
\text { (UFRN) }\end{array}$ & $\begin{array}{l}\text { Universidade } \\
\text { Federal do Rio } \\
\text { Grande do Sul } \\
\text { (UFRGS) }\end{array}$ & $\begin{array}{l}\text { Universidade } \\
\text { Federal } \\
\text { Fluminense } \\
\text { (UFF) }\end{array}$ & $\begin{array}{l}\text { Universidade } \\
\text { Gama Filho } \\
\text { (UGF) }\end{array}$ \\
\hline
\end{tabular}




\begin{tabular}{|c|c|c|c|}
\hline $\begin{array}{l}\text { Universidade } \\
\text { Metodista de } \\
\text { Piracicaba } \\
\text { (UNIMEP) }\end{array}$ & $\begin{array}{l}\text { Universidade } \\
\text { Nove de Julho } \\
\text { (UNINOVE) }\end{array}$ & $\begin{array}{l}\text { Universidade } \\
\text { Paranaense } \\
\text { (UNIPAR) }\end{array}$ & $\begin{array}{l}\text { Universidade } \\
\text { Presbiteriana } \\
\text { Mackenzie } \\
\text { (UPM) }\end{array}$ \\
\hline $\begin{array}{l}\text { Universidade } \\
\text { Regional do } \\
\text { Noroeste do } \\
\text { Estado do Rio } \\
\text { Grande do Sul } \\
\text { (UNJUÍ) }\end{array}$ & $\begin{array}{l}\text { Universidade } \\
\text { Regional do } \\
\text { Alto Uruguai } \\
\text { e das Missões } \\
\text { (URI) }\end{array}$ & $\begin{array}{l}\text { Universidade } \\
\text { Sagrado } \\
\text { Coração (USC) }\end{array}$ & \\
\hline
\end{tabular}

Em cada curso, procurou-se identificar em que instituição cada docente obteve sua maior titulação. Uma vez que para lecionar em programas de pós-graduação stricto sensu é necessário ter doutorado, a pesquisa revela em que instituição cada professor cursou seu doutorado. O formato dos dados permite distinguir a formação pós-doutoral do doutoramento. Para fins de contagem da influência e nucleação, focou-se apenas no doutoramento, por acreditar que a influência de nucleação é mais forte nesse período de formação e porque o mais interessante aqui é avaliar a nucleação de instituições nacionais. A nucleação por programas estrangeiros verificou-se em casos isolados, que serão relatados abaixo. ${ }^{3}$

Certos limites na metodologia utilizada devem ser indicados:

a) Nos casos em que o docente cursou doutorado em determinada instituição e livre-docência em outra, a titulação auferida é aquela informada pelo programa em que trabalha.

b) Quando o docente não possui doutorado, considerou-se o local de realização da maior titulação, seja qual for o título obtido.

De qualquer modo, tais limites foram considerados irrelevantes porque o número de docentes com livre-docência fora das universidades paulistas é mínimo, mesmo porque a livre-docência não é considerada de forma tão relevante em outras instituições. A maioria dos livre-docentes em direito são titulados pela mesma instituição em que cursaram o doutorado, com raras exceções. Da mesma forma, o número de docentes sem doutorado lecionando em programas de pós-graduação é insignificante dentro do espaço amostral.

\footnotetext{
${ }^{3}$ Os dados foram obtidos a partir da plataforma Sucupira, da Capes, que pode ser consultada no site https://sucupira.capes.gov.br/sucupira/public/consultas/coleta/programa/listaPrograma.jsf. Cada pesquisa gera informações próprias e não há um link com todos os dados compilados.
} 


\section{Dados obtidos}

Ao final de 2012, de acordo com os dados dos próprios programas, havia no Brasil 1774 professores de pós-graduação stricto sensu. O número de professores cresce com o aumento da pós-graduação. Nos anos 90, havia exclusividade de programas no Sul e Sudeste, com três exceções apenas: UnB, UFPA e UFPE. Agora, há programas de mestrado em mais de vinte unidades da federação.

Como era de se esperar, duas universidades concentram o maior número de professores em programas, a Universidade de São Paulo (USP) e a Pontifícia Universidade Católica de São Paulo (PUC-SP). A maior concentração nestas duas universidades decorre primeiro do número de doutores formados anualmente e, depois, da antiguidade de ambos os programas. Assim:

- A USP titulou 386 docentes, ouseja, 22\% do totaldos professores de programas do Brasil.

- A PUC-SP titulou 324 ou $18 \%$ do universo de docentes.

Contudo, é interessante notar que nem a USP, nem a PUC-SP formaram um número significativo de professores de qualquer outra região do país que não o próprio Estado de São Paulo. A vasta maioria dos professores de programas titulados nessas universidades lecionam no próprio Estado de São Paulo e há grande endogenia, na absorção dos professores que elas próprias formaram.

A seguir, apresenta-se os dados de cada programa do Brasil, por região.

- Região Centro - Oeste - Instituições de Ensino analisadas: Centro Universitário de Brasília (UNICEUB), o Instituto Brasiliense de Direito Público (IDP), Universidade Católica de Brasília (UCB), Universidade Federal do Goiás (UFG) e Universidade Federal do Mato Grosso (UFMT).

○ UNICEUB

- $28,43 \%$ dos docentes são titulados pela PUC-SP;

- $20,15 \%$ são titulados pela USP;

○ IDP

- $21,43 \%$ dos docentes são titulados pela UNB;

- $21,43 \%$ dos docentes são titulados pela USP;

○ UCB

- $18,75 \%$ dos docentes são titulados pela UNB;

- $18,75 \%$ dos docentes são titulados pela USP; 
$\circ$ UNB

- $22,73 \%$ dos docentes são titulados pela própria UNB;

- $15,91 \%$ dos docentes são titulados pela UFMG;

○ UFG

- $17,65 \%$ dos docentes são titulados pela PUC-SP;

- $17,65 \%$ dos docentes são titulados pela UFG;

○ UFMT

- $20,69 \%$ dos docentes são titulados pela PUC-SP;

- $13,79 \%$ dos docentes são titulados pela USP;

- Região Norte - Instituições de Ensino analisadas: Centro Universitário do Estado do Pará (CESUPA), Universidade Estadual do Amazonas (UEA) e Universidade Federal do Pará (UFPA).

- CESUPA

- $26,67 \%$ dos docentes são titulados pela UFPA;

- $20 \%$ dos docentes são titulados pela USP;

○ UEA

- $14,29 \%$ dos docentes são titulados pela PUC-SP;

- 7,14\% dos docentes são titulados pela UNB;

○ UFPA

- $26,92 \%$ dos docentes são titulados pela UFPA;

- $23,08 \%$ dos docentes são titulados pela PUC-SP;

- Região Nordeste - Instituições de Ensino analisadas: Centro Universitário do Maranhão (UNICEUMA), Universidade Católica de Pernambuco (UNICAP), Universidade de Fortaleza (UNIFOR), Universidade Federal da Bahia (UFBA), Universidade Federal Da Paraíba (UFPB), Universidade Federal de Alagoas (UFAL), Universidade Federal de Pernambuco (UFPE), Universidade Federal de Sergipe (UFS), Universidade Federal do Ceará (UFC), Universidade Federal do Maranhão (UFMA) e Universidade Federal do Rio Grande do Norte (UFRN).

- UNICEUMA

- $46,15 \%$ dos docentes são titulados pela PUC-SP;

- 23,08\% dos docentes são titulados pela UFPR;

- UNICAP

- $58,33 \%$ dos docentes são titulados pela UFPE;

- $16,67 \%$ dos docentes são titulados pela Universidade de Lisboa;

○ UNIFOR

- $40 \%$ dos docentes são titulados pela UFPE;

- $10 \%$ dos docentes são titulados pela UFMG;

○ UFBA

- $44,44 \%$ dos docentes são titulados pela PUC-SP;

- $11,11 \%$ dos docentes são titulados pela UFRJ;

○ UFPB

- $15,38 \%$ dos docentes são titulados pela UFPE; 
○

○ UFPE

- UFMA

- 33,33\% dos docentes são titulados pela PUC-SP;

○ UFRN

- $20 \%$ dos docentes são titulados pela UFSC;

- $33,33 \%$ dos docentes são titulados pela UFPE;

- $23,81 \%$ dos docentes são titulados pela PUC-SP;

- Região Sudeste - Instituições de Ensino analisadas: Centro Universitário Fieo (UNIFIEO), Centro Universitário Salesiano (UNISAL), Escola Superior Helder Câmara (ESDHC), Faculdade Antônio Carlos (UNIPAC), Faculdade Autônoma de Direito (FADISP), Faculdade de Direito de Vitória (FDV), Faculdade de Direito do Sul de Minas (FDSM), Faculdade de Direito Milton Campos (FAMC), Faculdades Metropolitanas Unidas (FMU), Fundação de Ensino Eurípides Soares da Rocha (UNIVEM), Fundação Getúlio Vargas (FGV), Instituição Toledo de Ensino (ITE), Pontifícia Universidade Católica de Minas Gerais (PUC-MG), Pontifícia Universidade Católica de São Paulo (PUC-SP), Pontifícia Universidade Católica do Rio de Janeiro (PUC-RJ), Universidade Cândido Mendes (UCAM), Universidade Católica de Petrópolis (UCP), Universidade Católica de Santos (UNISANTOS), Universidade de Itaúna (UI), Universidade de Marília (UNIMAR), Universidade de Ribeirão Preto (UNAERP), Universidade de São Paulo (USP), Universidade do Estado do Rio de Janeiro (UERJ), Universidade Estácio de Sá (UNESA), Universidade Estadual Paulista (UNESP), Universidade Federal de Minas Gerais (UFMG), Universidade Federal de Uberlândia (UFU), Universidade Federal do Espírito Santo (UFES), Universidade Federal do Estado do Rio de Janeiro (UNIRIO), Universidade Federal do Rio de Janeiro (UFRJ), Universidade Federal Fluminense (UFF), Universidade Gama Filho (UGF), Universidade Metodista de Piracicaba (UNIMEP), Universidade Nove de Julho (UNINOVE) e Universidade Presbiteriana Mackenzie (UPM).

○ UNIFIEO

- $51,14 \%$ dos docentes são titulados pela USP;

- $35,71 \%$ dos docentes são titulados pela PUC-SP;

- UNISAL

- $53,85 \%$ dos docentes são titulados pela PUC-SP; 
○ ESDHC

- $15,38 \%$ dos docentes são titulados pela UGF;

- $62,50 \%$ dos docentes são titulados pela UFMG;

- $25 \%$ dos docentes são titulados pela PUC-MG;

○ UNIPAC

- 61,54\% dos docentes são titulados pela UFMG;

- 15,38\% dos docentes são titulados pela UniversitéCatholique de Louvain;

○ FADISP

- 47,37\% dos docentes são titulados pela USP;

- 36,84\% dos docentes são titulados pela PUC-SP;

○ FDV

- $25 \%$ dos docentes são titulados pela USP;

- $20 \%$ dos docentes são titulados pela PUC-SP;

○ FDSM

- 33,33\% dos docentes são titulados pela USP;

- $16,67 \%$ dos docentes são titulados pela UFMG;

- FAMC

- $80 \%$ dos docentes são titulados pela UFMG;

- 5\% dos docentes são titulados pela PUC-MG;

○ FMU

- $66,67 \%$ dos docentes são titulados pela PUC-SP;

- $33,33 \%$ dos docentes são titulados pela USP;

○ UNIVEM

- 64,29\% dos docentes são titulados pela PUC-SP;

- $14,29 \%$ dos docentes são titulados pela UNESP;

○ FGV

- 82,35 dos docentes são titulados pela USP;

- $11,76 \%$ dos docentes são titulados pela PUC-SP;

○ ITE

- 70,59\% dos docentes são titulados pela PUC-SP;

- $11,76 \%$ dos docentes são titulados pela UFOP;

○ PUC-MG 
- 70,21\% dos docentes são titulados pela UFMG;

- $17,02 \%$ dos docentes são titulados pela PUC-MG;

○ PUC-SP

- $85,57 \%$ dos docentes são titulados pela PUC-SP;

- 9,28\% dos docentes são titulados pela USP;

○ PUC-RJ

- $21,74 \%$ dos docentes são titulados pela UERJ;

- $17,39 \%$ dos docentes são titulados pela PUC-SP;

○ UCAM

- $25 \%$ dos docentes são titulados pela USP;

- $15 \%$ dos docentes são titulados pela UGF;

○ UCP

- 41,67\% dos docentes são formados pela UGF;

- $25 \%$ dos docentes são formados pela PUC-RJ;

○ UNISANTOS

- 62,50\% dos docentes são titulados pela USP;

- $25 \%$ dos docentes são titulados pela PUC-SP;

$\circ$ UI

- 23,53\% dos docentes são titulados pela PUC-MG;

- $17,65 \%$ dos docentes são titulados pela PUC-SP;

○ UNIMAR

- $66,67 \%$ dos docentes são titulados pela PUC-SP;

- $16,67 \%$ dos docentes são titulados pela UNESP;

○ UNAERP

- 64,29\% dos docentes são titulados pela PUC-SP;

- 21,43\% dos docentes são titulados pela UNESP;

○ USP

- 90,78\% dos docentes são titulados pela USP;

- 3,40\% dos docentes são titulados pela PUC-SP;

○ UERJ

- $41,10 \%$ dos docentes são titulados pela UERJ;

- $13,70 \%$ dos docentes são titulados pela USP; 
○ UNESA

- $40 \%$ dos docentes são titulados pela UERJ;

- $20 \%$ dos docentes são titulados pela UFG;

○ UNESP

- 34,07\% dos docentes são titulados pela UNESP;

- $22,22 \%$ dos docentes são titulados pela PUC-SP;

○ UFMG

- 94,12\% dos docentes são titulados pela UMGF;

- $1,96 \%$ dos docentes são titulados pela PUC-RJ;

$\circ \quad \mathrm{UFU}$

- $25 \%$ dos docentes são titulados pela PUC-SP;

- $25 \%$ dos docentes são titulados pela UFMG;

○ UFES

- $28,57 \%$ dos docentes são titulados pela PUC-SP;

- $14,29 \%$ dos docentes são titulados peça USP;

○ UNIRIO

- 41,10\% dos docentes são titulados pela UERJ;

- $13,70 \%$ dos docentes são titulados pela USP;

○ UFRJ

- $11,33 \%$ dos docentes são titulados pela PUC-SP;

- $11,33 \%$ dos docentes são titulados pela PUC-RJ;

○ UFF

- $38,89 \%$ dos docentes são titulados pela UERJ;

- $11,11 \%$ dos docentes são titulados pela UFSC;

○ UGF

- $44,44 \%$ dos docentes são titulados pela UERJ;

- $11,11 \%$ dos docentes são titulados pela UGF;

○ UNIMEP

- $50 \%$ dos docentes são titulados pela USP;

- $50 \%$ dos docentes são titulados pela PUC-SP;

- UNINOVE

- $44 \%$ dos docentes são titulados pela PUC-SP; 
- $44,44 \%$ dos docentes são titulados pela USP;

○ UPM

- $70 \%$ dos docentes são titulados pela USP;

- $25 \%$ dos docentes são titulados pela PUC-SP;

- Região Sul: Centro Universitário Curitiba (UNICURITIBA), Centro Universitário Ritter dos Reis (UNIRITTER), Faculdades Integradas do Brasil (UNIBRASIL), Pontifícia Universidade Católica do Paraná (PUCPR), Pontifícia Universidade Católica do Rio Grande do Sul (PUCRGS), Universidade de Santa Cruz do Sul (UNISC), Universidade do Vale do Itajaí (UNIVALI), Universidade do Vale do Rio dos Sinos (UNISINOS), Universidade Estadual de Londrina (UEL), Universidade Estadual do Norte do Paraná (UENP), Universidade Federal de Santa Catarina (UFSC), Universidade Federal do Paraná (UFPR), Universidade Federal do Rio Grande do Sul (UFRGS), Universidade Paranáense (UNIPAR), Universidade Regional do Noroeste do Estado do Rio Grande do Sul (UNIJUI), Universidade Regional Integrada do Alto Uruguai e das Missões (URI) e Universidade Sagrado Coração (USC).

- UNICURITIBA

- $62,50 \%$ dos docentes são titulados pela UFPR;

- $31,25 \%$ dos docentes são titulados pela PUC-SP;

○ UNIRITTER

- 71,43\% dos docentes são titulados pela UFRGS;

- $14,29 \%$ dos docentes são titulados pela USP;

○ UNIBRASIL

- $66,67 \%$ dos docentes são titulados pela UFPR;

- 6,67\% dos docentes tão titulados pela PUC-SP;

○ PUCPR

- $57,50 \%$ dos docentes são titulados pela UFPR;

- $10 \%$ dos docentes são titulados pela PUC-SP;

○ PUCRGS

- $15,56 \%$ dos docentes são titulados pela UFRGS;

- $11,11 \%$ dos docentes são titulados pela PUC-RS; 
○ UNISC

- $43,75 \%$ dos docentes são titulados pela UNISINOS;

- $25 \%$ dos docentes são titulados pela UFSC;

○ UNIVALI

- $42,56 \%$ dos docentes são titulados pela UFSC;

- $14,29 \%$ dos docentes são titulados pela UA;

○ UNISINOS

- $26,37 \%$ dos docentes são titulados pela UNISINOS;

- $15,79 \%$ dos docentes são titulados pela UFSC;

$\circ$ UEL

- 62,50\% dos docentes são titulados pela PUC-SP;

- $12,50 \%$ dos docentes são titulados pela USP;

○ UENP

- $38,46 \%$ dos docentes são titulados pela PUC-SP;

- $15,38 \%$ dos docentes são titulados pela USP;

○ UFSC

- 56,67\% dos docentes são titulados pela UFSC;

- $6.67 \%$ dos docentes são titulados pela UFPR;

○ UFPR

- $57,50 \%$ dos docentes são titulados pela UFPR;

- $10 \%$ dos docentes são titulados pela PUC-SP;

○ UFRGS

- $36 \%$ dos docentes são titulados pela UFRGS;

- $20 \%$ dos docentes são titulados pela USP;

○ UNIPAR

- 78,57\% dos docentes são titulados pela PUC-SP;

- $14,29 \%$ dos docentes são titulados pela UFPR;

○ UNIJUI

- $30,77 \%$ dos docentes são titulados pela UNISINOS;

- $15,38 \%$ dos docentes são titulados pela UFRGS;

○ URI

- $26,67 \%$ dos docentes são titulados pela UFSC; 
- $20 \%$ dos docentes são titulados pela UNISINOS;

○ USC

- $22,22 \%$ dos docentes são titulados pela UFRGS;

- $16,67 \%$ dos docentes são titulados pela UNISINOS;

\section{Discussão dos dados}

Os dados permitem concluir que, na área de Direito, no Brasil, nenhuma instituição tem realmente predominância em âmbito nacional. Em cada região, há uma escola que predomina e de forma geral, nessa escola, o corpo docenteé majoritariamente formado por ela própria, com forte endogenia.

No Brasil, nenhum programa exerce de fato nucleação. Os dados mostram que em alguns casos, $10 \%$ a $20 \%$ do corpo docente é da USP ou da PUC-SP, o que não significa nucleação, porque são programas pequenos, com 10 a 14 docentes, ou seja, há dois ou três professores formados nos programas grandes, o que não revela "forte influência".

Na região Centro-Oeste, predomina a Universidade de Brasília, sobretudo nos Estados com programas mais novos, como em Mato Grosso e em Goiás. Contudo, o curso de doutorado da UnB tem poucos anos e vários dos doutores que lecionam em outros programas no Centro-Oeste não são titulados em Direito, mas em outras áreas afins. No UNICEUB, por exemplo, havia cinco doutores pela UnB, sendo formados em desenvolvimento sustentável, sociologia, antropologia e história, mas nenhum em direito.

Na região Norte, a Universidade Federal do Pará formou a maior parte dos doutores dos poucos programas existentes. Como a UFPA é a única instituição que oferece doutorado, comprova-se a sua importância regional. Uma vez que é conhecida a existência de doutorandos do Norte do Brasil nos programas do Sudeste e Sul, apenas se pode concluir que os investimentos na formação desses profissionais não significa melhoria do ensino da sua região de origem. Em outras palavras, ou os doutorandos oriundos dessas regiões não voltam para suas origens para lecionar após a titulação. Ficam nos Estados em que se titularam ou, se voltam, não mais se dedicam a pós- graduação. 
Na região Nordeste, a Universidade Federal de Pernambuco é predominante em quase todos os programas existentes, o que demonstra que de fato houve êxito na construção de uma escola com influência regional, mais do que outras grandes do Sudeste. A única exceção é o programa novo do Maranhão, que teve influência significativa de docentes titulados pela PUC-SP e pela USP.

Nas duas regiões com maior número de programas tradicionais, a realidade é bastante peculiar. No Sul e Sudeste, não há influencias sequer regionais, mas estaduais. Em cada Estado, há um ou dois programas do próprio Estado que titulou os professores dos Programas do seu próprio Estado e nada além disso. Ao contrário do que se poderia imaginar, estes fortes programas estaduais têm pouca ou nenhuma relevância na composição do corpo docente de outros programas de outros Estados.

Assim, em Minas Gerais, predomina a UFMG, à frente da PUC-MG, por exemplo. No Rio de Janeiro, a maioria dos titulados vem do programa da UERJ. No Rio Grande do Sul, há forte influência da UFRGS. No Paraná, a maior parte dos titulados vem da UFPR.

UNISINOS，PUC-RS，PUC-PR，PUC-Rio tem influência muito baixa na composição do corpo docente de outros programas, seja porque formaram poucos doutores, seja porque os doutores que formaram não foram absorvidos por outras instituições.

Um caso interessante é São Paulo, com predominância da USP e da PUC-SP, mas com muito pouco contato entre si. Como se mostrou acima, estas são as escolas que mais formaram professores em todo o país. Contudo, a participação de professores titulados em outros programas nessas IES predominantes é quase insignificante, o que revela forte endogenia. Os dados chamam atenção, porque embora os dois programas fiquem a algumas centenas de metros um do outro, na mesma cidade, os egressos de um programa são quase inexistentes no outro:

- $\quad 90,78 \%$ dos professores da USP se titularam na própria USP e apenas $3,40 \%$ se titularam na PUC-SP.

- $85,57 \%$ dos professores da PUC-SP se titularam na própria PUC-SP e apenas $9,28 \%$ na USP.

O mesmo ocorre nas demais universidades tradicionais estaduais, em que os índices de endogenia são expressivos: 
- $94,12 \%$ dos docentes da UFMG são titulados pela UMGF;

- $57,50 \%$ dos docentes são titulados pela UFPR;

- $56,67 \%$ dos docentes da UFSC são titulados pela própria UFSC

- $41,10 \%$ dos docentes da UERJ são titulados pela UERJ

A análise dos dados não avalia todas as possibilidades possíveis de cooperação. Outras pesquisas empíricas, podriam tentar avaliar "1) pesquisas conjuntas, (2) produção intelectual compartilhada, (3) realização de eventos científicos, (4) disciplinas compartilhadas, (5) intercâmbio de professores, (6) intercâmbio de estudantes e (7) participação em comissões examinadoras ${ }^{4}$. São todas formas de cooperação, mas que não buscam identificar propriamente o conceito de nucleação acadêmica, tal como desenvolvido pela Capes.

\section{Considerações finais}

A pós-graduação brasileira é regional. Ela se universaliza com base em docentes disponíveis localmente, formados no curso de doutorado mais próximo. Não há nenhuma universidade que consiga ter forte influência nacional. Mesmo as grandes universidades têm apenas um ou dois professores titulados em diferentes programas.

Além disso, nota-se que mesmo localmente, há pouca comunicação de talentos entre as universidades tradicionais, sobretudo na USP, na PUC-SP e na UFMG. A tradição é absorver seus próprios titulados e não criar mecanismos de diálogo na composição do corpo docente.

Infelizmente, esse cenário dificulta a produção coletiva do conhecimento e a troca de experiências entre as universidades. A formação de redes de pesquisa interinstitucionais como método de produção coletiva do saber precisa ser estimulada. Isso parte, de um lado, na circulação do conhecimento e, de outro, na vontade de conhecer, dar oportunidades e absorver o conhecimento produzido pelos colegas do mesmo país. $\mathrm{N}$

\footnotetext{
${ }^{4}$ Guimarães, T. A et alii. A rede de programas de pós-graduação em administração no Brasil: análise de relações acadêmicas e atributos de programas in Revista de Administração Contemporanea v. 13, n. 4, 2009, disponível no site:http://www.scielo.br/scielo.php?script=sci_arttext\&pid=S1415$65552009000400004 \&$ Ing=pt\&nrm=iso\&tlng=pt
} 


\section{Referências}

Guimarães, T. A et alii. A rede de programas de pós-graduação em administração no Brasil: análise de relações acadêmicas e atributos de programas in Revista de Administração Contemporanea v. 13, n. 4, 2009, disponível no site:http://www.scielo.br/scielo.php?script=sci_arttext\&pid=S141565552009000400004\&lng=pt\&nrm=iso\&tlng=pt

VARELLA, M. D. e BARRETO, M. M. Políticas de revalidação de diplomas de pós-graduação em Direito no Brasil: dificuldades e desafios para o sistema brasileiro in Revista Brasileira de Polítcas Públicas, v. 2, n. 1p. 143-161 